\title{
Combination immunotherapy in the treatment of chronic bilateral panuveitis and uveitic glaucoma during acute dengue fever infection in the Caribbean
}

\author{
This article was published in the following Dove Press journal: \\ International Medical Case Reports Journal \\ 23 July 2015 \\ Number of times this article has been viewed
}

\author{
Kevin P Stewart ${ }^{1,2}$ \\ Jan B Tawakol ${ }^{3,4}$ \\ Tasnim Khan ${ }^{3,4}$ \\ Joseph A Capriotti ${ }^{1,2}$ \\ 'Plessen Ophthalmology Consultants, \\ ${ }^{2}$ Department of Surgery, Juan F Luis \\ Hospital, ${ }^{3}$ Plessen Healthcare, LLC \\ ${ }^{4}$ Department of Medicine, Juan F Luis \\ Hospital, Christiansted, United States \\ Virgin Islands
}

\begin{abstract}
Background: Ocular manifestations of the dengue fever virus include bilateral panuveitis that can occur after the acute systemic infection has resolved. In most reported cases, the inflammation resolves with topical or systemic steroid therapy. We report a case of chronic, refractory bilateral panuveitis and uveitic glaucoma that began during the acute phase of the systemic infection and required treatment with oral steroids, multiple steroid-sparing agents, and surgical therapy for glaucoma.

Findings: A 22-year-old male with acute systemic dengue fever presented with bilateral pain and decreased vision. Clinical examination revealed bilateral panuveitis with elevated intraocular pressures. Management required oral steroids, mycophenolate mofetil, cyclosporine, and bilateral glaucoma valve implantation.

Conclusion: This case highlights the fact that dengue-associated panuveitis can begin in the acute stage of systemic infection and persist long after convalescence with progression to chronic bilateral panuveitis and uveitic glaucoma. Dengue-associated chronic panuveitis with uveitic glaucoma may be effectively managed with a combination of steroid-sparing oral immunosuppression and glaucoma surgery. This is, to our knowledge, the first case of bilateral refractory dengue-associated panuveitis from the Caribbean treated with combination steroid-sparing oral immunosuppression and bilateral glaucoma valve implantation.
\end{abstract}

Keywords: mycophenolate mofetil, cyclosporine A, Ahmed glaucoma valve

\section{Introduction}

Dengue fever is caused by a virus in the Flaviviridae family transmitted by the Aedes aegypti and Aedes albopictus mosquitoes. The acute systemic phase of the infection is marked by pyrexia, malaise, and joint pain. ${ }^{1}$ The disease has been seen with increasing frequency in the past decade, particularly in the Caribbean and parts of the developing world. ${ }^{2}$ Myriad ocular manifestations have been reported, although the most common involve the posterior segment. Cotton-wool spots, macular edema, and vascular occlusions are often encountered. Anterior segment involvement most commonly includes subconjunctival hemorrhages from thrombocytopenia during the acute phase of the infection. ${ }^{3}$ Anterior chamber inflammation and iridocyclitis are less common, with ciliary congestion being noticeably absent in the majority of cases. The time course of ocular involvement is frequently during the acute systemic phase of the infection, but has also been reported in some cases months after the primary infection has resolved. ${ }^{4}$ Bilateral involvement is not common. ${ }^{5}$
Correspondence: Joseph A Capriotti Plessen Ophthalmology Consultants, PO Box 598I, Christiansted 00820, United States Virgin Islands Tel +l 3407732015

Email jacapriottimd@gmail.com 


\section{Case report and discussion}

A 22-year-old male of Caribbean descent presented to our clinic with complaints of diminished vision, pain, and photosensitivity in the right eye (OD) for several weeks. He was currently suffering through the acute phase of dengue fever, which had been diagnosed by his primary care provider and confirmed with serology. The patient had severe arthralgia, malaise, headache, pyrexia, and severe dehydration. There was no thrombocytopenia. His dengue infection was confirmed with an elevated dengue fever IgM performed at a contract reference laboratory (LAbCorp, Tampa, FL, USA) on two separate occasions separated by several weeks. His visual acuity, unimproved with refraction, was 20/80 OD and 20/60 in the left eye (OS). Intraocular pressures were $46 \mathrm{mmHg}$ OD and $44 \mathrm{mmHg}$ OS. Slit-lamp examination was notable for pronounced ciliary flush; large, nongranulomatous keratic precipitates; scattered anterior synechiae; and 3+ anterior chamber cell OD, while the slit-lamp exam of the left anterior segment was unremarkable except for mild ciliary flush. There was an anterior vitritis present in both eyes, with significantly greater vitreous opacity OD than OS. Dilated fundus examination revealed a dense core vitritis, pars planitis, and significant neuroretinitis OD, with a milder vitritis, mild neuroretinal folds, and mild pars planitis OS. Both optic nerves appeared to have enlarged cup-to-disc ratios, although examination was limited due to vitreous opacity. The presumptive diagnosis of bilateral panuveitis was made, and a comprehensive lab workup was initiated to locate any other causative etiology. After a normal chest radiograph, treatment was started with oral prednisone $80 \mathrm{mg}$ orally once a day (PO QD), topical timolol, topical acetazolamide, and topical cycloplegia. Response to oral steroid was excellent, and a follow-up examination at 1 week showed nearly complete resolution of the vitritis and neuroretinitis. The intraocular pressures, however, had risen to over $60 \mathrm{mmHg}$ in both eyes, and there was persistent anterior chamber cell and flare OD. Topical timolol was continued along with the initiation of an oral prednisone taper, and oral acetazolamide was added. After another week with no change in oral prednisone dosage at $60 \mathrm{mg} \mathrm{PO} \mathrm{QD}$, the vitritis and retinitis returned OU with worsening vision to CF OD, 20/100 OS, and persistently elevated pressures. While increasing the oral and topical steroid over the following 2 weeks was effective at resolving the inflammation, oral acetazolamide and maximal topical hypotensives were inadequate to control the rising intraocular pressures. It was presumed that there was both an inflammatory glaucoma and a steroid-induced glaucoma response. Steroid-sparing therapy was a primary goal and, for this reason, mycophenolate mofetil was added and raised to
$3 \mathrm{~g}$ per day. ${ }^{6,7}$ It was decided that the complete cessation of oral steroid was an important treatment goal given what we believed to be a mixed-mechanism glaucoma with some contribution from a hypertensive steroid response in a very young patient. As the oral steroids were tapered, every time the dose was decreased to $60 \mathrm{mg}$ PO QD or lower, the inflammation again returned, and oral cyclosporine $\mathrm{A}$ was added in addition to the mycophenolate mofetil. With addition of cyclosporine A, the inflammation was completely controlled. Combination treatment with both mycophenolate mofetil and cyclosporine $\mathrm{A}$ allowed us to completely taper off oral prednisone and topical prednisolone without the recurrence of any inflammation. The intraocular pressures decreased from the sixties to the forties, but still could not be medically managed to an acceptable range. In our practice, we generally prefer Ahmed glaucoma valve implants as first-line drainage procedures in inflammatory glaucomas due to their long-term lower incidence of postoperative hypotony compared to Baerveldt implants. ${ }^{8}$ Bilateral Ahmed implants (FP7) were placed 4 days apart OD and OS. The intraocular pressure was stabilized in the low teens without the need for topical or oral hypotensives. Visual acuity returned to 20/25 OD and 20/20 OS within 1 month of Ahmed glaucoma implantation. All anterior and posterior inflammation has to date been controlled without the need for further topical or systemic corticosteroid therapy.

\section{Conclusion}

Dengue-associated uveitis with onset during the acute systemic phase of the infection can have long-term ocular effects including bilateral panuveitis. Despite symptoms being reported in only one eye, bilateral cases can occur with asymmetric involvement of each eye. Multiple steroidsparing agents can be used to control anterior and posterior inflammation when cessation of oral steroids is of primary importance. Early surgical intervention for mixed inflammatory and steroid-induced ocular hypertension can be a useful tool for managing high intraocular pressures and need not be delayed until the cessation of all inflammation. Management of these complicated cases benefits from an aggressive surgical approach, diligent pursuit of steroid-sparing agents, and collaboration with an experienced medical team to help guide and manage the careful use of multiple immunomodulatory agents.

\section{Author contributions}

All authors edited and approved the manuscript. All authors have seen and treated this patient. Both JAC and KPS performed surgery in this case. All authors contributed toward 
data analysis, drafting and critically revising the paper and agree to be accountable for all aspects of the work.

\section{Disclosure}

The authors report no conflicts of interest in this work.

\section{References}

1. World Health Organization (WHO). Dengue and severe dengue. Fact sheet No 117 [homepage on the Internet]. Geneva: WHO; 2002 [updated, 2015]. Available from: http://www.who.int/mediacentre/factsheets/fs117/ en/. Accessed April 4, 2015.

2. Gibbons RV, Vaughn DW. Dengue: an escalating problem. BMJ. 2002;324:1563-1566
3. Lim WK, Mathur R, Koh A, Yeoh R, Chee SP. Ocular manifestations of dengue fever. Ophthalmology. 2004;111:2057-2064.

4. Gupta A, Srinivasan R, Setia S, Soundravally R, Pandian DG. Uveitis following dengue fever. Eye (Lond). 2009;23:873-876.

5. Chan DP, Teoh SC, Tan CS, et al; Eye Institute Dengue-Related Ophthalmic Complications Workgroup. Ophthalmic complications of dengue. Emerg Infect Dis. 2006;12:285-289.

6. Baltatzis S, Tufail F, Yu EN, Vredeveld CM, Foster CS. Mycophenolate mofetil as an immunomodulatory agent in the treatment of chronic ocular inflammatory disorders. Ophthalmology. 2003;110:1061-1065.

7. Teoh SC, Hogan AC, Dick AD, Lee RW. Mycophenolate mofetil for the treatment of uveitis. Am J Ophthalmol. 2008;146:752-760.

8. Christakis PG, Tsai JC, Kalenak JW, et al. The Ahmed versus Baerveldt study: three-year treatment outcomes. Ophthalmology. 2013;120(11): $2232-2240$

\section{Publish your work in this journal}

The International Medical Case Reports Journal is an international, peer-reviewed open-access journal publishing original case reports from all medical specialties. Previously unpublished medical posters are also accepted relating to any area of clinical or preclinical science. Submissions should not normally exceed 2,000 words or
4 published pages including figures, diagrams and references. The manuscript management system is completely online and includes a very quick and fair peer-review system, which is all easy to use. Visit http://www.dovepress.com/testimonials.php to read real quotes from published authors.

Submit your manuscript here: http://www.dovepress.com/international-medical-case-reports-journal-journal 